Tema: Aciaria Elétrica

\title{
ESTUDO DE ENSAIOS ESTÁTICOS E CINÉTICOS NA PREVISÃO E PREVENÇÃO DA DRENAGEM ÁCIDA DE MINERAÇÃO, COM O USO DE ESCÓRIA DE ACIARIA ELÉTRICA DO FORNO PANELA COM REJEITO DE CARVÃO*
}

\section{Resumo}

Luciana Angelita Machado ${ }^{1}$ Luísa Venuto de Freitas ${ }^{2}$ Pedro Ivo Villetti ${ }^{2}$

Rejane Maria Candiota Tubino ${ }^{3}$ Ivo André Homrich Schneider ${ }^{4}$

Os rejeitos gerados na mineração de carvão, sob condições atmosféricas e a possível presença de bactérias acidofílicas proporcionam a oxidação primária do sulfeto de ferro, formando sulfatos e ácido sulfúrico. Com a redução do $\mathrm{pH}$ da água, ocorre a mobilização de metais contidos no material, gerando a drenagem ácida de mina (DAM). A DAM causa um impacto nocivo na qualidade da água superficial ou subterrânea. Uma das tecnologias de prevenção da geração da DAM consiste no método de aditivos alcalinos. Assim, o objetivo do presente trabalho foi avaliar o controle da DAM pela mistura de rejeito de carvão com escória de aciaria elétrica do forno panela. A metodologia utilizada baseou-se nos ensaios estáticos e ensaios cinéticos. Os resultados demonstram que o rejeito de carvão gera DAM. Contudo os problemas ambientais podem ser em grande parte resolvidos pela mistura do rejeito com a escória na proporção acima de 10:10. Os ensaios cinéticos demonstram que, nessa condição, ocorre aumento do pH e redução do potencial redox e sulfatos na água lixiviada. Desta forma, a disposição conjunta de escória de aciaria elétrica do forno panela com rejeito de carvão é uma alternativa viável para o controle da geração de DAM em minerações de carvão.

Palavras-chave: Drenagem ácida de mina; Escória de aciaria; Mineração de carvão

\section{STATIC AND KINETIC TESTS STUDY FOR THE PREDICTION AND PREVENTION OF ACID MINING DRAINAGE, WITH THE USE OF LADLE SLAG OF ELECTRIC STEELMAKING MIXED WITH COAL WASTE}

\section{Abstract}

The waste generated in coal mining, under atmospheric conditions and the possible presence of acidophilic bacteria provides the primary oxidation of iron sulfide, forming sulfates and sulfuric acid. With the reduction of the water $\mathrm{pH}$, the mobilization of metals contained in the material occurs, generating acid mine drainage (AMD). The AMD causes an adverse impact on surface or groundwater quality. One of the technologies to prevent the AMD is the alkaline additives method. The objective of this study was to evaluate the AMD control by mixing tailings with the ladle slag of electric steelmaking. The used methodology was based on static tests and kinetic assays. The results demonstrate that coal tailings generates AMD. However, the environmental problems can be largely solved by mixing the waste with the slag in the ratio of 10:10. The kinetic experiments demonstrate that, in this condition, there is an increase of $\mathrm{pH}$ and a reduction on the redox potential and in the sulphate in the leach water. Thus, the combined disposal of ladle slag of electric steelmaking with coal waste is a viable alternative to control the generation of AMD in coal mining.

Keywords: Acid mine drainage; Steel slag; Coal mining.

Doutoranda, PPGE3M, Escola de Engenharia, UFRGS, Porto Alegre, RS, Brasil.

Graduando em Engenharia Ambiental, Escola de Engenharia, UFRGS, Porto Alegre, RS, Brasil.

Professora Doutora, DEMET e PPGE3M, Escola de Engenharia, UFRGS, Porto Alegre, RS, Brasil.

Professor Doutor, DEMIN e PPGE3M, Escola de Engenharia UFRGS, Porto Alegre, RS, Brasil.

\footnotetext{
* Contribuição técnica ao $45^{\circ}$ Seminário de Aciaria - Internacional, 25 a 28 de maio de 2014,
} 


\section{INTRODUÇÃO}

Os processos de extração e beneficiamento na mineração geram uma grande quantidade de resíduos. O mais preocupante é decorrente da drenagem ácida de minas (DAM), a qual resulta de reações químicas de sulfetos metálicos na presença de ar e água. Este tipo de reação é comum em áreas de mineração de carvão, uma vez que a pirita e a marcassita (ambos $\mathrm{FeS}_{2}$, porém em formas cristalinas distintas) são encontrados nas jazidas de carvão. Os poluentes da DAM afetam a qualidade da água, baixando o seu potencial hidrogeniônico $(\mathrm{pH})$, reduzindo a alcalinidade natural, aumentando a dureza total e acrescentando quantidades indesejáveis de ferro, manganês, alumínio, sulfatos e, eventualmente, outros metais. Estas fontes permanecem ativas por décadas e até mesmo por séculos após a sua produção $[1,2]$.

A disposição inadequada de rejeitos e estéreis de mineração de carvão com potencial de geração de DAM é um dos problemas ambientais enfrentados pela indústria da mineração no sul do país, especialmente no Rio Grande do Sul e Santa Catarina. Esta é uma questão bastante séria e vem requerendo estudos no sentido de encontrar soluções que venham a minimizar os danos causados ao meio ambiente.

No estado do Rio Grande do Sul, materiais alcalinos são empregados em depósitos de rejeitos de carvão para minimizar a geração de DAM, método este conhecido como "controle da DAM por aditivos alcalino" [2]. Tendo em vista a minimização e reaproveitamento de resíduos, a escória de aciaria do forno panela, um resíduo da produção de aço, pode ser uma alternativa a ser empregada como aditivo alcalino no controle da DAM.

A aplicação da técnica de adição de resíduos alcalinos pode ser avaliada em laboratório através de ensaios estáticos pelo método de contabilização de ácidos e base (acid-base accounting method - ABA) [3]. Os ensaios estáticos permitem quantificar a relação exata entre resíduos alcalinos e rejeitos de mineração para que ocorra a neutralização.

Desse modo, o objetivo do presente trabalho foi estudar a prevenção da geração da DAM pela adição de escória de aciaria do forno panela a rejeitos de carvão. Estes estudos foram realizados pela contabilização de minerais geradores de acidez no rejeito de carvão e pela determinação do potencial de neutralização da escória de aciaria do forno panela.

\section{MATERIAIS E MÉTODOS}

As amostras de escória de aciaria elétrica do forno panela foram obtidas de uma usina siderúrgica semi-integrada que produz aços especiais, localizada no Estado do Rio Grande do Sul. As amostras de rejeito de carvão foram obtidas de uma Mina de Carvão, que minera a Camada Barro Branco no Estado de Santa Catarina, após o beneficiamento gravimétrico por jigagem. As amostragens do rejeito de carvão e da escória de aciaria foram realizadas visando obter uma amostra representativa, durante um turno de operação da mineradora e da siderúrgica, seguiram os procedimentos descritos na NBR 10007 [4]. Após a coleta, as amostras foram transportadas para o Laboratório de Estudos Ambientais para a Metalurgia (LEAmet), no Centro de Tecnologia (CT) da Universidade Federal do Rio Grande do Sul (UFRGS), para realização das operações de secagem, homogeneização, quarteamento, peneiramento, cominuição, análise e realização dos experimentos.

As análises de metais do rejeito de carvão e da escória de aciaria elétrica do forno panela foram realizadas com abertura de amostra pelo método EPA 3052 [5] e a leitura por espectrofotometria de absorção atômica (Equipamento Varian AA1275). As amostras foram analisadas em relação ao teor de cinzas, matéria volátil e carbono fixo. As análises de cinzas foram realizadas conforme a NBR 8289 [6]. A matéria volátil foi determinada seguindo a norma NBR 8290 [7]. Os valores obtidos foram corrigidos em relação ao teor de umidade. As análises do teor de umidade foram realizadas conforme NBR 8293 [8]. A determinação do carbono fixo foi realizada por diferença, subtraindo-se de cem a soma das porcentagens de umidade, cinzas e matérias voláteis [9].

\footnotetext{
* Contribuição técnica ao $45^{\circ}$ Seminário de Aciaria - Internacional, 25 a 28 de maio de 2014, Porto Alegre, RS, Brasil.
} 
Os ensaios estáticos foram realizados pelo método de contabilização de ácidos e bases (ABA - do inglês, Acid Base Accounting). A finalidade foi determinar o balanço entre a produção de acidez e o consumo de acidez (neutralização) pelos componentes minerais da amostra de rejeito de carvão e da escória [3,10] (EPA, 1994, SOBEK et al, 1978). Para a realização dos ensaios estáticos, foram realizados testes preliminares: determinação do $\mathrm{pH}$ da pasta, com o objetivo de identificar as condições de acidez ou alcalinidade das amostras, e o teste Fizz, para definir o volume e a concentração de ácido clorídrico a ser empregado na determinação do potencial de neutralizaçãos [3,10]. A determinação do potencial de acidez (AP) foi realizada seguindo a metodologia descrita na norma D 5373 [11]. Para a determinação do potencial de neutralização (NP), o procedimento consistiu em submeter a amostra a uma solução ácida (conforme valores determinados pelo teste Fizz) seguido da titulação da solução ácida com hidróxido de sódio (com a mesma concentração do ácido) até $\mathrm{pH}$ 7,0. A partir dos valores determinados do AP e NP calcula-se, por diferença, o potencial de neutralização líquido (NNP), expresso em $\mathrm{kg} \mathrm{CaCO}_{3} \mathrm{t}^{-1}$ de amostra. Valores de NNP $<20$ indicam que o material gera DAM, valores de NNP $>20$ indicam que o material não gera a DAM, e valores de NNP entre -20 e 20 demonstram uma situação indefinida $[12,13]$.

Os ensaios cinéticos foram realizados pelo método de células úmidas, conforme procedimento D 5744 [14]. Foram utilizadas quatro células úmidas para realização do ensaio cinético. Uma célula foi preenchida somente com rejeito de carvão e outra célula somente com escória de aciaria elétrica do forno panela. As outras duas células foram preenchidas com mistura de materiais na proporção rejeito de carvão:escória na proporção de 10:10 (para conferir um NNP igual a zero) e na proporção de 10:15. A mistura dos materiais foi realizada de forma a conferir a maior homogeneidade possível entre as amostras. Os ensaios consistiram em colocar uma amostra de aproximadamente 1000 gramas com granulometria inferior a $6,3 \mathrm{~mm}$ em um frasco fechado, com ciclos de exposição das amostras por três dias ao ar seco, três dias ao ar úmido e um dia para lavagem com água destilada $(500 \mathrm{~mL})$. Após a lavagem das células, o lixiviado foi coletado e analisado em relação aos parâmetros de qualidade de água: $\mathrm{pH}$, potencial redox e sulfato. As análises foram realizadas semanalmente, seguindo os procedimentos do Standard Methods for the Examination of Water and Wastewater [15]. O período de ensaio, recomendado em no mínimo de 20 semanas pela norma D 5744 [14], foi de 80 semanas.

\section{RESULTADOS E DISCUSSÃO}

A Tabela 1 apresenta os resultados da análise elementar do rejeito de carvão e na escória de aciaria elétrica do forno panela. Pode-se observar que o rejeito de carvão é rico em enxofre, silício, ferro e alumínio. Diante deste contexto, faz-se necessário um controle do rejeito de carvão para que os metais e o enxofre presentes não sejam lixiviados para o meio ambiente, gerando drenagem ácida de mina. No caso da escória de aciaria elétrica do forno panela, os elementos químicos que estão em maior concentração são alumínio, cálcio, ferro, manganês, magnésio e silício. A presença de cádmio, cromo, cobalto, cobre, níquel e chumbo também foi detectada, mas em concentrações menores.

\footnotetext{
* Contribuição técnica ao $45^{\circ}$ Seminário de Aciaria - Internacional, 25 a 28 de maio de 2014, 
Tabela 1. Resultado da composição elementar do rejeito de carvão (RC) e da escória de aciaria elétrica do forno panela (EAE-FP), \% em massa.

\begin{tabular}{|c|c|c|}
\hline Elemento & $\mathrm{RC}(\%)$ & EAE-FP (\%) \\
\hline $\mathrm{C}$ & 4,72 & 2,16 \\
\hline $\mathrm{H}$ & 1,19 & 0,58 \\
\hline $\mathrm{N}$ & 0,13 & 0,02 \\
\hline $\mathrm{S}$ & 10,60 & 0,03 \\
\hline O e EM & 36,30 & 47,95 \\
\hline $\mathrm{Al}$ & 4,50 & 1,56 \\
\hline As & 0,006 & 0,009 \\
\hline $\mathrm{Ca}$ & 0,71 & 11,93 \\
\hline $\mathrm{Cd}$ & 0,0001 & 0,001 \\
\hline Co & 0,003 & 0,001 \\
\hline $\mathrm{Cl}$ & - & 0,006 \\
\hline $\mathrm{Cr}$ & 0,003 & 0,37 \\
\hline $\mathrm{Cu}$ & 0,003 & 0,007 \\
\hline $\mathrm{F}$ & - & 0,53 \\
\hline $\mathrm{Fe}$ & 7,31 & 8,83 \\
\hline $\mathrm{K}$ & 1,01 & 0,06 \\
\hline $\mathrm{Mg}$ & 0,02 & 3,34 \\
\hline $\mathrm{Mn}$ & 0,016 & 1,15 \\
\hline $\mathrm{Na}$ & 0,15 & 0,02 \\
\hline $\mathrm{Ni}$ & 0,003 & 0,009 \\
\hline $\mathrm{P}$ & 0,02 & 0,06 \\
\hline $\mathrm{Pb}$ & 0,009 & 0,0006 \\
\hline $\mathrm{Si}$ & 26,88 & 21,40 \\
\hline $\mathrm{Zn}$ & 0,009 & 0,02 \\
\hline
\end{tabular}

EM: Elementos Minoritários

A Tabela 2 apresenta a análise imediata da escória de aciaria elétrica do forno panela e do rejeito de carvão em termos de cinzas, matéria volátil, umidade, carbono fixo e enxofre total, em base seca. Pode-se observar que a escória de aciaria elétrica do forno panela apresenta $100 \%$ de cinzas, $1,7 \%$ de matéria volátil, $0 \%$ de carbono fixo e $0,0 \%$ de enxofre total. O rejeito de carvão apresenta $81,3 \%$ de cinzas, $12,3 \%$ de matéria volátil, $5,1 \%$ de carbono fixo e $10,6 \%$ de enxofre total. Os resultados obtidos para o rejeito de carvão estão concordantes com pesquisa realizada por Menezes [16] com rejeito de carvão do mesmo tipo e local. O autor encontrou teor de cinza 80,4\%, 12,4\% de matéria volátil, 7,1\% carbono fixo e 9,7\% de enxofre total.

Tabela 2. Resultado da análise imediata da escória de aciaria elétrica do forno panela e do rejeito de carvão

\begin{tabular}{|ccccc|}
\hline Parâmetro & Cinzas (\%) & Matéria Volátil (\%) & $\mathrm{C}_{\text {Fixo }}(\%)$ & $\mathrm{S}_{\text {Total }}(\%)$ \\
\hline RC & 81,3 & 12,3 & 5,1 & 10,6 \\
EAE-FP & 100,0 & 1,7 & 0,0 & 0,0 \\
\hline
\end{tabular}

O resultado do $\mathrm{pH}$ da pasta referente à escória de aciaria elétrica do forno panela foi de 11,7 , indicando a alta alcalinidade. $\mathrm{O} \mathrm{pH}$ da pasta referente ao rejeito de carvão foi de 5,3, mostrando a tendência do material em gerar ácido. O teste Fizz, por meio da classificação do som efervescente produzido, apresentou resultado "moderado",

* Contribuição técnica ao 450 Seminário de Aciaria - Internacional, 25 a 28 de maio de 2014, 
para a escória e "nenhum" para o rejeito de carvão. A intensidade do som no teste Fizz está relacionada com a presença de minerais consumidores de ácido (cabonatos ou óxidos de cálcio e magnésio), quanto maior for o som, maior será a quantidade de minerais consumidores de ácido contidos na amostra.

Os resultados de contabilização do potencial de geração de acidez e do potencial de neutralização dos materiais estão apresentados na Tabela 3. O valor do AP e do NP da amostra de escória foi de 1,0 e 353,1 $\mathrm{kg} \mathrm{CaCO}_{3} \mathrm{t}^{-1}$, respectivamente. O valor do NNP foi de $352,1 \mathrm{~kg} \mathrm{CaCO} \mathrm{Ca}^{-1}$. O NNP positivo indica que a amostra não irá gerar ácido. O rejeito de carvão apresentou um AP de $331,2 \mathrm{~kg} \mathrm{CaCO}_{3} \mathrm{t}^{-1}$ e um NP de 6,8 $\mathrm{kg} \mathrm{CaCO}_{3} \mathrm{t}^{-1}$, o que resultou em um NNP negativo de $-324,4 \mathrm{~kg} \mathrm{CaCO}_{3} \mathrm{t}^{-1}$, indicando que o material irá gerar DAM na presença de ar e água. Com base nos resultados de NNP, estabeleceu-se também a proporção de mistura. A relação obtida foi de 10 toneladas de rejeito de carvão para 11 toneladas da escória. Em termos práticos, esse valor de mistura foi arredondado para uma proporção RC:EAE-FP 10:10 de rejeito de carvão para escória. Além desta proporção, empregou-se também a proporção RC:EAE-FP 10:15 para observar se o acréscimo de material alcalino, como fator de segurança de $50 \%$, teria um resultado superior na qualidade do lixiviado.

Tabela 3 - Resultados de ensaios estáticos para a escória de aciaria elétrica do forno panela e do rejeito de carvão

\begin{tabular}{|c|c|c|c|c|c|}
\hline Parâmetro & pH em pasta & Teste Fizz & $\begin{array}{l}\text { AP } \\
\mathrm{kg}\end{array}$ & $\mathrm{t}^{-1} \mathbf{N P}$ & NNP \\
\hline $\begin{array}{c}\mathrm{RC} \\
\mathrm{EAE}-\mathrm{FP}\end{array}$ & $\begin{array}{c}5,3 \\
11,7\end{array}$ & $\begin{array}{c}\text { nenhum } \\
\text { moderado }\end{array}$ & $\begin{array}{c}331,2 \\
1,0\end{array}$ & $\begin{array}{c}6,8 \\
353,1\end{array}$ & $\begin{array}{c}-324,4 \\
352,1\end{array}$ \\
\hline
\end{tabular}

As Figuras de 1 a 3 apresentam os resultados do ensaio cinético em quatro células úmidas, bem como os resultados dos parâmetros físico-químicos dos lixiviados coletados semanalmente: potencial hidrogeniônico, potencial redox e sulfato.

A Figura 1 mostra os resultados referentes ao potencial hidrogeniônico - pH da água lixiviada. A água lixiviada da célula contendo somente rejeito de carvão é ácida, com valores de $\mathrm{pH}$ iniciais em torno de 3,3 e decrescendo chegando na semana $33 \mathrm{com}$ $\mathrm{pH}$ 0,9, estabilizando-se nas semanas seguintes em torno de 2,0. Estudos realizados por Farfan et al. [17] reportam que os valores de $\mathrm{pH}$ abaixo de 4,0 e as elevadas concentrações de metais, são considerados os componentes mais críticos da DAM, comportamento este que também pode ser observado nas análises dos lixiviados da célula com rejeito de carvão. Ainda de acordo com os autores, estas situações ocasionam reações de oxidação aumentando a toxicidade no entorno, e atuando de forma prejudicial à fauna aquática. $\mathrm{O} \mathrm{pH}$ da água lixiviada da célula contendo somente EAE-FP apresentou valores elevados de $\mathrm{pH}$ na faixa de $11,0 \mathrm{a}$ 6,0 . Estes resultados confirmam os resultados dos ensaios estáticos, comprovando que o lixiviado extraído desta célula é alcalino.

$\mathrm{Na}$ célula contendo a mistura dos materiais na proporção RC:EAE-FP 10:10 os valores foram alcalinos, ficando na faixa de 9,0 a 6,0, com exceção das semanas 26; 68; 69 e 75 que ficou próximo de 5,5. Pode-se observar pelas análises do pH que a proporção de RC:EAE-FP 10:10 fornecida pelo método ABA tradicional permite a neutralização da água de percolação, nas oitenta semanas de ensaio ficando com $\mathrm{pH}$ neutro ou levemente alcalino. Estes resultados estão de acordo com os observados por Ferguson e Morin [18] em ensaios laboratoriais conduzidos por um tempo mais longo, com NP/AP próximo de um, não haverá a formação de ácido.

O lixiviado da célula com a proporção RC:EAE-FP 10:15, o pH até a vigésima semana ficou acima de 8,1 com valores máximos de 10,7 (semana 1), a partir da semana 21 os valores de pH ficaram na faixa de 6,0 a 8,0 . As leituras de $\mathrm{pH}$ do lixiviado mostraram que em todas as semanas do experimento os valores do $\mathrm{pH}$

* Contribuição técnica ao $45^{\circ}$ Seminário de Aciaria - Internacional, 25 a 28 de maio de 2014, Porto Alegre, RS, Brasil. 


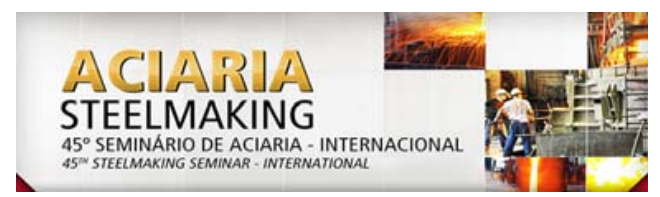

foram superiores aos valores encontrados para a mistura RC:EAE-FP 10:10, mas analisando a variação do pH durante as semanas o comportamento foi semelhante em ambas as células, iniciando com pH mais elevado, com o passar do tempo diminuindo, sendo que a partir da semana 42 os valores do $\mathrm{pH}$ para os dois lixiviados foram semelhantes. A utilização de uma concentração maior de RC:EAEFP mostrou-se mais eficiente nas primeiras 20 semanas, sendo que nas semanas seguintes teve comportamento semelhante ao do lixiviado com menor proporção de EAE-FP, não apresentando diferenças significativas quanto aos valores absolutos encontrados ao final do ensaio.

Conclui-se com base nas análises do $\mathrm{pH}$ do lixiviado das células úmidas durante as 80 semanas de ensaio cinético, que o rejeito de carvão gera DAM, pois seu pH foi relativamente baixo em todas as análises. A EAE-FP é alcalina, seu $\mathrm{pH}$ foi elevado, como esperado. A mistura de rejeito de carvão com escória de aciaria elétrica na proporção de RC:EAE-FP 10:10 é efetiva na melhoria das condições de pH, comparando os resultados do pH com o rejeito de carvão, nota-se uma elevação do pH com a utilização da escória, comprovando a eficiência técnica da mesma.

Os valores de $\mathrm{pH}$ encontrados para os lixiviados das células RC:EAE-FP 10:10 e RC:EAE-FP 10:15 foram comparados aos padrões de lançamento de efluentes que dispõe a CONAMA 430 [19] para descarte de efluente. Segundo esta norma, os efluentes somente poderão ser lançados nos corpos de água se o pH estiver entre 5 a 9. Portanto, a mistura RC:EAE-FP 10:15, nas primeiras semanas ficou com pH acima dos padrões estabelecidos, mas a mistura RC:EAE-FP 10:10 atende para o lançamento do efluente com relação ao $\mathrm{pH}$, a quantidade de material alcalino utilizada foi suficiente para elevar $\mathrm{o} \mathrm{pH}$ do lixiviado aos níveis estabelecidos pela legislação durante todo o experimento.
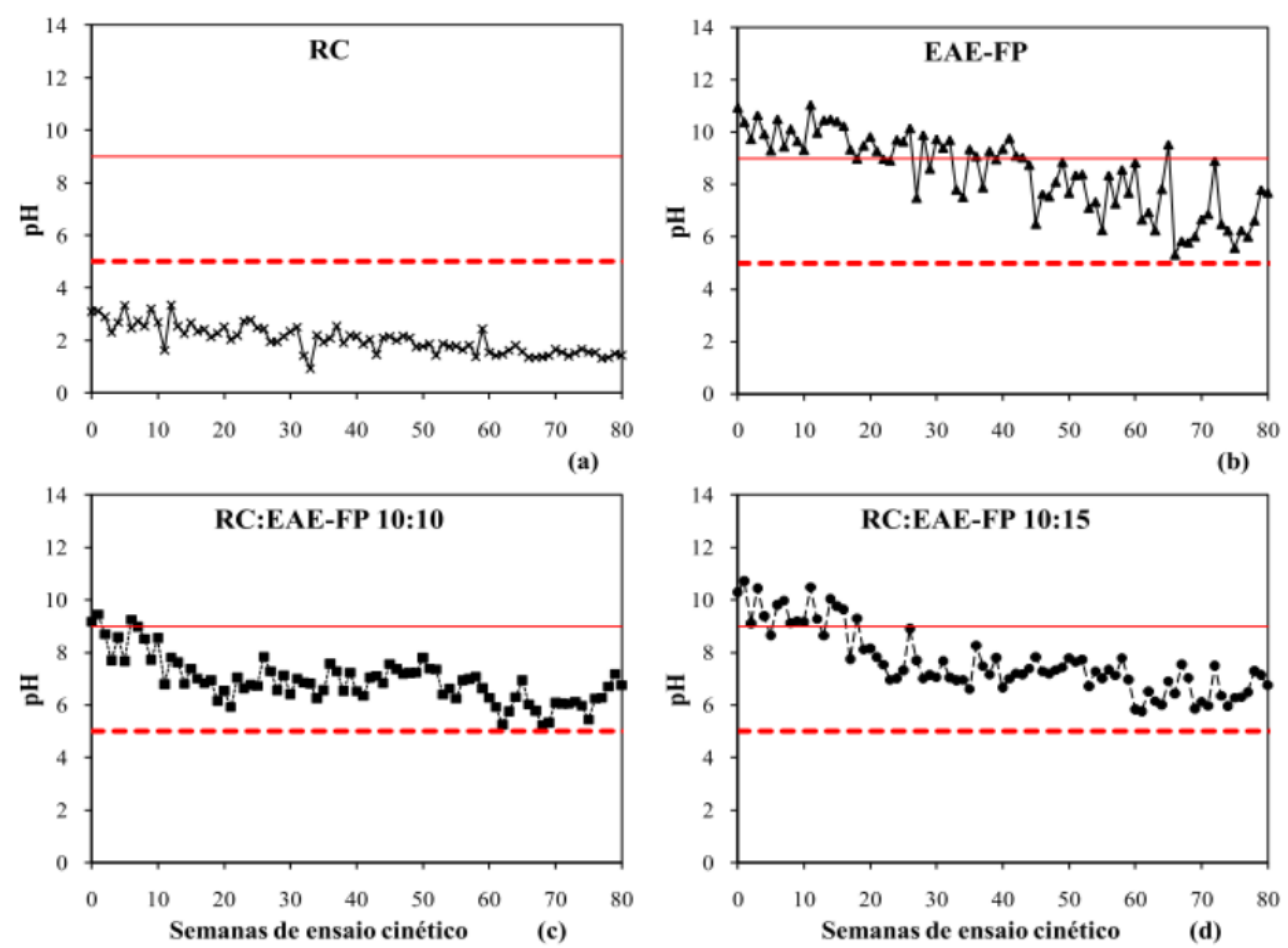

Figura 1. Valores de pH nos lixiviados das células úmidas com rejeito de carvão (RC), escória de aciaria elétrica do forno panela (EAE-FP), rejeito de carvão com escória de aciaria elétrica do forno panela na proporção 10:10 (RC:EAE-FP 10:10) e na proporção 10:15 (RC:EAE-FP 10:15), valor mínimo (---) e máximo (-) permitido pela CONAMA 430 [19] para lançamento de efluente

* Contribuição técnica ao $45^{\circ}$ Seminário de Aciaria - Internacional, 25 a 28 de maio de 2014, Porto Alegre, RS, Brasil. 
A Figura 2 apresenta os resultados do potencial redox para os lixiviados analisados no ensaio cinético. A análise do lixiviado proveniente da célula contendo apenas rejeito de carvão permaneceu com valores elevados durante o experimento, entre 862 a $613 \mathrm{mV}$, demonstrando uma condição altamente oxidante que favorece a degradação de sulfetos e indicam a ocorrência da DAM na água lixiviada desta célula. De acordo com Mend Program [20], valores de potencial redox superiores a $450 \mathrm{mV}$ e $\mathrm{pH}$ inferior a 3,5 indicam um ambiente oxidante, influenciado pela presença da bactéria Acidithiobacillus ferrooxidans, e valores de potencial redox superiores a $500 \mathrm{mV}$ promovem a oxidação do íon $\mathrm{Fe}^{+3}$, que favorece a oxidação da pirita, que podem ser confirmados pelas concentrações elevadas de sulfato, acidez e ferro presente no lixiviado da célula com rejeito de carvão durante todo o experimento. Enquanto que os valores do potencial redox do lixiviado da célula com EAE-FP são menores que os valores do lixiviado do rejeito de carvão, com variação na faixa de 312 a $605 \mathrm{mV}$ da semana zero a semana 80, indicando que as condições de oxidação nesta célula são inferiores a da célula com rejeito de carvão.

O lixiviado da mistura na proporção RC:EAE-FP 10:10 houve variações, com valores mínimos de $208 \mathrm{mV}$ (semana 21 e 23) e máximos chegando a $592 \mathrm{mV}$ (semana 77). Com relação à análise do lixiviado da célula com a proporção RC:EAE-FP 10:15, ficou entre 533 a $290 \mathrm{mV}$, pode-se observar que não houve grandes variações no potencial redox durante as semanas analisadas. De qualquer forma, apesar de haver picos de variação do potencial redox, para as proporções, não houve tendência nítida de variação do potencial redox no decorrer do tempo de análise. Conforme observado por Domenico e Schwartz [21] o potencial redox esta relacionado com a capacidade de redução e oxidação e com a presença de íons dissolvidos na água de lixiviação, quanto maior for a quantidade de íons dissolvidos no lixiviado, maior será os valores do potencial redox, sendo assim o lixiviado da célula de rejeito de carvão é o que apresenta os maiores valores de potencial redox, logo é a célula que apresenta maior oxidação, enquanto que o lixiviado das células com mistura dos materiais, tanto na proporção de RC:EAE-FP 10:10 quanto na proporção de RC:EAE-FP 10:15 os valores do potencial redox foram menores que no lixiviado da célula com rejeito, consequentemente a quantidade de íons dissolvido nestas células foram menores.
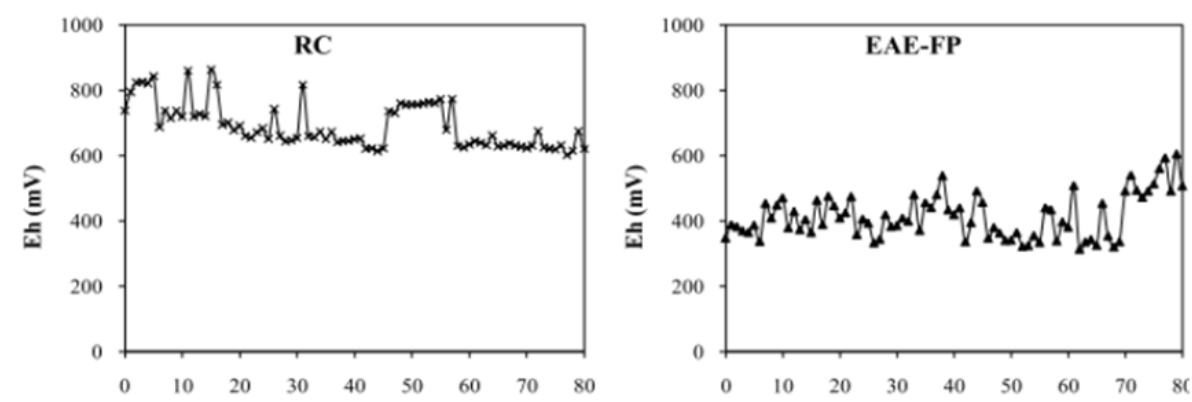

(a)

(b)
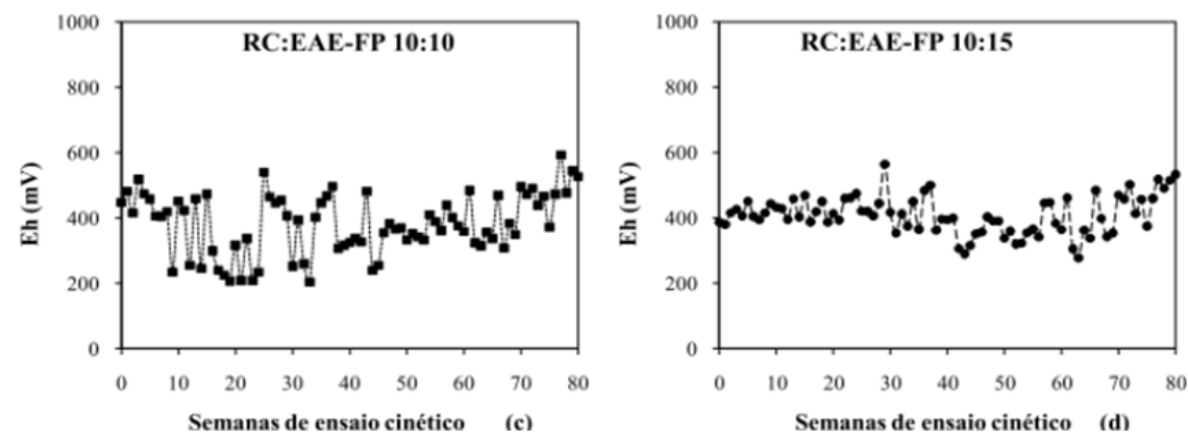

Figura 2. Valores de potencial redox nos lixiviados das células úmidas com rejeito de carvão (RC), escória de aciaria elétrica do forno panela (EAE-FP), rejeito de carvão com escória de aciaria elétrica do forno panela na proporção 10:10 (RC:EAE-FP 10:10) e na proporção 10:15 (RC:EAE-FP 10:15)

\footnotetext{
* Contribuição técnica ao 450 Seminário de Aciaria - Internacional, 25 a 28 de maio de 2014, Porto Alegre, RS, Brasil.
} 
A Figura 3 mostra os resultados referentes às análises da extração de sulfato no lixiviado das células úmidas. Nas alíquotas obtidas da célula com o rejeito de carvão a concentração de sulfato ficou na faixa de 1701,4 a $6254,0 \mathrm{mg} \mathrm{kg}^{-1}$ de RC na maioria da semanas, sendo que em algumas semanas a concentração de sulfato dissolvido nos lixiviados em função do tempo, foi elevada com valores extraídos de 7368,0; 8639,1; 7310,9 e 8952,1 $\mathrm{mg} \mathrm{kg}^{-1}$ de RC, nesta ordem de ocorrência para as semanas: 51; 67; 71 e 74.

Os resultados obtidos da concentração de sulfato no lixiviado coletado da célula com EAEFP apresentou baixa extração de sulfato, com extrações máxima na semana 28 de 325,6 mg kg-1 e mínimas de $0,0 \mathrm{mg} \mathrm{kg}^{-1}$ nas semanas 48 a $57 ; 74 ; 78$ a 80 , nas semanas seguintes ficou na faixa de $100 \mathrm{mg} \mathrm{kg}^{-1}$. Com base no estudo realizado por Casas e Crecelius [22] em ambientes ricos em ferro os sulfatos vão se precipitando como sulfetos de ferro (FeS e $\mathrm{FeS}_{2}$ ), pode-se aferir os resultados da extração de sulfato ser maior no lixiviado da célula com rejeito de carvão e menor da célula com EAE-FP.

Os lixiviados da mistura de RC:EAE-FP 10:10 na semanas zero a 47 os valores extraídos foram decaído de 855,1 a $445,7 \mathrm{mg} \mathrm{kg}^{-1}$, sendo que as maiores quantidades extraídas foram nas semanas 19; 21 e 23 com extração de 715,2; 834,4 e 784,2 $\mathrm{mg} \mathrm{kg}^{-1}$, respectivamente, a partir da semana 48 as concentrações de sulfato ficaram em torno de $350 \mathrm{mg} \mathrm{kg}^{-1}$. Ao relacionar as quantidades de sulfatos extraídas nesta célula com as quantidades extraídas na célula do rejeito de carvão, as quantidades foram menores, durante todo o ensaio, demonstrando que a adição de EAE-FP inibiu a liberação de sulfato, podendo ser usada no controle da prevenção da DAM.

As quantidades de sulfato lixiviadas da célula com proporção de RC:EAE-FP 10:15, foram menores em todas as análises que as encontradas no lixiviado da mistura de RC:EAE-FP 10:10. Demonstrando que na relação RC:EAE-FP 10:15 é mais eficiente na redução da oxidação da pirita e na liberação de sulfato.

De forma geral, foi verificado através do ensaio cinético que a maioria dos elementos analisados no lixiviado apresentou mobilidade mais elevada no lixiviado da célula do rejeito de carvão, sugerindo um potencial poluidor significativo deste resíduo em relação ao lixiviado das demais células. Os dados indicam que a presença da EAE-FP nas dosagens de RC:EAE-FP 10:10 e RC:EAE-FP 10:15, elevou o pH e a alcalinidade do meio, diminuindo a acidez, as concentrações de sulfato e metais, além de reduzir o potencial de oxidação, provavelmente reduzindo as condições de oxidação da pirita. Esses dados estão de acordo com conclusões de Capanema e Ciminelli [23], que observaram valores elevados de potencial redox favorecem a oxidação de materiais sulfetados, com a decorrente diminuição do $\mathrm{pH}$ da água lixiviada. Esse fato está associado ao $\mathrm{pH}$ mais elevado do meio, que inibe a oxidação da pirita, reduz a solubilidade dos metais e favorece os processos de adsorção de compostos metálicos na matéria mineral [24,25].

\footnotetext{
* Contribuição técnica ao $45^{\circ}$ Seminário de Aciaria - Internacional, 25 a 28 de maio de 2014,
} 

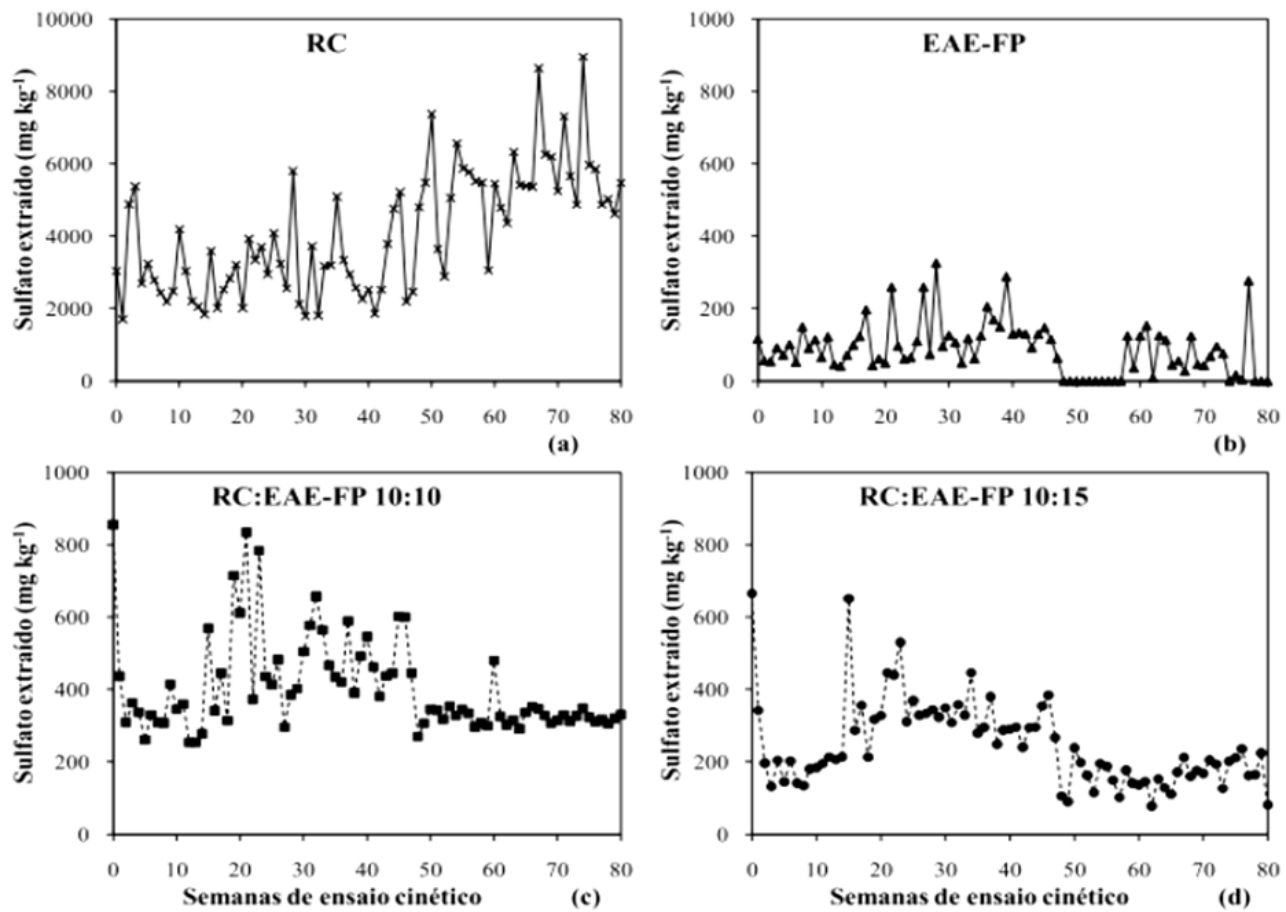

Figura 3. Concentração de sulfato nos lixiviados das células úmidas com rejeito de carvão (RC), escória de aciaria elétrica do forno panela (EAE-FP), rejeito de carvão com escória de aciaria elétrica do forno panela na proporção 10:10 (RC:EAE-FP 10:10) e na proporção 10:15 (RC:EAE-FP 10:15)

\section{CONCLUSÕES}

Baseado nos resultados obtidos na presente pesquisa as amostras de rejeitos de carvão têm potencial de geração de acidez, aumentando o potencial de geração de DAM. A escória de aciaria elétrica do forno panela possui potencial de neutralização, podendo ser utilizada como material alcalino para evitar a DAM. É importante enfatizar que a utilização de uma proporção 10:10 de rejeito de carvão misturado com escória de aciaria elétrica do forno panela é suficiente para elevar o $\mathrm{pH}$ e diminuir o potencial redox e a liberação de sulfato. Ou seja, a escória estudada é eficaz na prevenção da geração de DAM. Portanto, misturas de rejeitos de carvão e escória do forno panela de aciaria elétrica apresentam potencial para minimizar a geração de DAM.

\section{REFERÊNCIAS}

1 Skousen J, Rose A, Geidel G, Foreman J, Hellier WA. A handbook of technologies for avoidance and remediation of acid mine drainage. West Virginia University and the National Mine Land Reclamation Center, 1998.

2 Kontopoulos A. Acid Mine Drainage Control. In: Effluent treatment in the mining industry. Castro SH, Vergara F, Sánchez MA (Eds.). University of Concepciòn, 1998: 57-118.

3 Environmental Protection Agency - EPA. EPA 530-R-94-036: Technical Document. Acid Mine Drainage Prediction, 1994. Technical Document.

4 Associação Brasileira De Normas Técnicas - ABNT. NBR 10007: Amostragem de resíduos sólidos . Rio de Janeiro, 2004.

5 Environmental Protection Agency - EPA. EPA SW-846: Method 3052: Microwave assisted acid digestion of siliceous and organically based matrices. Revision 3. Washington, 2004.

6 Associação De Normas Técnicas - ABNT. NBR 8289: determinação do teor de cinza.

* Contribuição técnica ao $45^{\circ}$ Seminário de Aciaria - Internacional, 25 a 28 de maio de 2014, Porto Alegre, RS, Brasil. 


\section{ACIARIA}

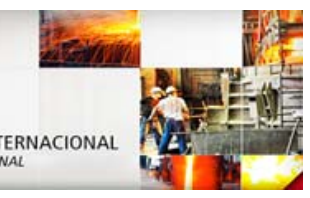

Rio de Janeiro, 1983.

7 Associação De Normas Técnicas - ABNT. NBR 8290: determinação do teor de matérias voláteis. Rio de Janeiro; 1983.

8 Associação De Normas Técnicas - ABNT. NBR 8293: determinação de umidade. Rio de Janeiro; 1983.

9 Associação De Normas Técnicas - ABNT. NBR 8299 - Carvão mineral: determinação do carbono fixo. Rio de Janeiro; 1983.

10 Sobek AA, Schuller WA, Freeman JR, Smith RM. Field and Laboratory Methods Applicable to Overburden and Minesoils, EPA 600/2-78-054, 1978.

11 American Society For Testing And Material - ASTM. ASTM D 5373: test method for carbon and hydrogen in the analysis sample of coal and coke. USA, 2002.

12 Lawerence RW, Wang Y. Determination of Neutralization Potential in the Prediction of Acid Rock Drainage. In: Proceeding... 4th International Conference on Acid Rock Drainage. MEND, Natural Resources Canada, Ottawa, 1997: 449-464.

13 Adam K, Koutis A, Gazea B, Kontopoulos, A. Evaluation of static tests used to predict the potential for acid drainage generation at sulfide mine sites. Transactions of the Institution of Mining and Metallurgy, 1997.

14 American Society For Testing And Material - ASTM. ASTM D 5744. Standard test method for accelerated weathering of solid materials using a modified humidity cell. 1996.

15 American Public Health Association - APHA. Standard methods for the examination of water and wastewater. 21th Edition. Washington D.C.: APHA-AWWA-WEF, 2005.

16 MENEZES, J. C. S. S. Produção de coagulantes férricos na mineração de carvão. Tese de Doutorado. Escola de Engenharia. Programa de Pós-Graduação em Engenharia de Minas, Metalurgia e de materiais - PPGE3M, Universidade federal do Rio Grande do Sul - UFRGS, Porto Alegre, RS, 2009.

17 Farfan JRJZ, Barbosa FO, De Souza VP. Avaliação do potencial de drenagem ácida de rejeitos da indústria mineral. Rio de Janeiro: CETEM/MCT, 2004.

18 Farfan JRJZ, Barbosa FO, De Souza VP. Avaliação do potencial de drenagem ácida de rejeitos da indústria mineral. Rio de Janeiro: CETEM/MCT, 2004.

19 Ministério Da Ciência E Tecnologia - BRASIL. Conselho Nacional do Meio Ambiente (CONAMA). Resolução CONAMA nº 430. Brasília: 2011.

20 MEND PROGRAM. Environment Canada, acid rock drainage prediction manual. MEND. Projeto de relatório 1.16.1b CANMET, Ottawa, 1991.

21 Domenico PA, Schwartz F W. Physical and chemical hydrogeology. Wiley \& Sons. New York.1990.

22 Casas AM, Crecelius E A. Relationship between acid volatile sulfide and the toxicity of zinc lead and copper in marine sediments. Environ. Toxical. Chem., 1994;13:529-536.

23 Capanema LXL, Ciminelli VST. An investigation of acid rock drainage (ARD) occurrence in a gold mine located in a Southeastern Brazil region. Revista Escola de Engenharia, Ouro Preto, 2003; 56 (3): 201-206.

24 Simmons J, Ziemkiewicz P, Black DC. Use of steel slag leach bedsfor the treatment of acid mine drainage. Mine Water and the Environment, 2002;21:91-99.

25 Feng D, Van Deventer JSJ, Aldrich C. Removal of Pollutants from acid mine wastewater using metallurgical by-products slags. Separation and Purification Technology, 2004;56(3):359-68. 